\title{
Auxotypes and antimicrobial susceptibilities of Neisseria gonorrhoeae in black and white patients
}

\author{
R.OBERT C NOBLE AND BETTY R MILLER \\ From the Division of Infectious Diseases, Department of Medicine, University of Kentucky College of \\ Medicine, Lexington, Kentucky, USA
}

SUMMARY Isolates of Neisseria gonorrhoeae from 100 white and 113 black patients attending a venereal disease clinic were examined for their susceptibility to ampicillin, penicillin, tetracycline, and spectinomycin. The isolates were also characterised by gonococcal auxotyping. Gonococcal isolates from black patients were more resistant to the antibiotics than those from white patients, since the former were infected with the more antibiotic-resistant auxotypes (Pro, Zero, and Arg) whereas the latter were infected with the more antibiotic-susceptible auxotypes (AHU and others). These data indicate a preferential infection by sub-populations of Neisseria gonorrhoeae in two racial groups.

\section{Introduction}

Despite the availability of effective antimicrobial therapy, gonococcal infections continue to be a major public health problem. Epidemiological investigations have shown that gonorrhoea occurs more commonly in black patients than in white patients attending venereal disease clinics in the United States. ${ }^{1-3}$ It is not known if this is due to behavioural, genetic, or some other biological phenomenon. One possible explanation is that gonococci infecting black and white patients differ in certain critical properties that would be disadvantageous to black individuals, such as the susceptibility of the gonococci to antibiotics used in treatment. Patients who are infected with gonococci that are relatively resistant to certain antibiotics have a higher treatment failure rate than individuals infected with less resistant isolates. ${ }^{4}$ Such inadequately treated patients may remain infectious and continue to contribute to the total number of cases of gonorrhoea. If antibiotic-resistant gonococci occurred more frequently in black patients, this might partly explain the increased incidence of gonorrhoea in black populations.

Our study was designed to examine gonococci isolated from black and white patients attending a

Address for reprints: Dr R C Noble, Division of Infectious Diseases Department of Medicine, University of Kentucky College of Medicine, Lexington, Kentucky 40536, USA

Received for publication 12 April 1979 venereal disease clinic and to test the susceptibility of the gonococci to antimicrobial agents used in treatment. The gonococci were further characterised by auxotyping. ${ }^{5}$

\section{Patients and methods}

BACTERIAL ISOLATES

Isolates of Neisseria gonorrhoeae were cultured from 213 patients with uncomplicated gonorrhoea (138 men, 75 women) attending the Lexington-Fayette County Health Department between December 1973 and December 1977. At the time of registration in the clinic, the patients completed an admission form which included a designation of race as either white or non-white. Black patients accounted for almost all the patients in the non-white category. Clinic attendances by Indians, Orientals, or other racial groups were rare because of the geographical location of the clinic.

Only one isolate was studied from a single patient and the culture sites included urethra, cervix, or rectum. All isolates were obtained before antibiotic therapy. The cultures were taken with cotton swabs and incubated for 48 hours at $36^{\circ} \mathrm{C}$ on modified Thayer-Martin medium containing vancomycin, colistin, nystatin, and trimethoprim. ${ }^{6}$ All gonococci were identified by bacterial morphology, Gram stain, oxidase reaction ( $1 \%$ solution of $\mathrm{N}, \mathrm{N}$-dimethyl-pphenylenediamine monohydrochloride), and the production of acid with dextrose- but not maltose-, lactose-, sucrose-, or fructose-containing media. 
Gonococcal isolates were stored at $-70^{\circ} \mathrm{C}$ in tryptic soy broth containing $13 \%$ glycerol.

\section{ANTIBIOTIC SUSCEPTIBILITY TESTING}

Antibiotic susceptibility testing was performed using the plate dilution technique. ${ }^{4}$ Strains of $N$ gonorrhoeae (F18 and F29) and Sarcinia lutea (F20) with known antibiotic susceptibilities (provided by Dr Clyde Thornsberry, Center for Disease Control, Atlanta, Georgia) were included as controls when gonococcal isolates were tested for their antibiotic susceptibilities. The antibiotics (purchased from the United States Pharmacopeial Convention Inc., Bethesda, Maryland) were tested in the following concentrations by means of two-fold dilutions in agar: ampicillin and penicillin 0.007-2 $\mu \mathrm{g} / 1$; tetracycline $0 \cdot 09-25 \mu \mathrm{g} / 1$; and spectinomycin $0 \cdot 39-100 \mu \mathrm{g} / \mathrm{l}$.

\section{AUXOTYPING}

Gonococcal auxotyping was performed on each isolate, and gonococci of known type were included with each batch. Single isolates of four different auxotypes (Zero, Thi, Pro-Hyx, Pro-Met-ThPP) (supplied by Dr Karen Carifo and Dr B Wesley Catlin, Medical College of Wisconsin) were used.

\section{STATISTICAL METHODS}

The $\chi^{2}$ test was used in the analysis of categorical data. The Wilcoxin-Mann-Whitney $U$ test (twotailed) and the Kruskal-Wallis one-way analysis of variance were used in the analysis of the antibiotic susceptibility data. ${ }^{7}$ The second and third tests included corrections for tied observations.

\section{Results}

One hundred and thirteen patients identified themselves as black and 100 patients as white. Gonococcal isolates from black patients were significantly more resistant to ampicillin, penicillin, tetracycline, and spectinomycin than those from the white patients (Table I). The percentages of the auxotypes of gonococci isolated from the black and white patients are shown in Table II. The auxotypes of the gonococci differed significantly between the racial groups. Gonococci of the auxotypes, Pro, Zero, and Arg, were isolated more frequently from black patients whereas gonococci of the auxotypes, Arg-Hyx-Ura and "others", were isolated more frequently from whites. The latter category contained the following auxotypes; two Pro-Arg, one Pro-Met, five Pro-Arg-Hyx-Ura, one Arg-MetHyx-Ura, one Arg-Hyx-Pro, three Arg-Orn-HyxUra, and two Arg-Orn. In addition, gonococci of the five auxotype groups differed in their susceptibility to the four antibiotics (Table III). The gonococci of auxotypes, Pro, Zero, and Arg, were more resistant to the antibiotics whereas those of the Arg-Hyx-Ura and other auxotypes were more susceptible.

Within any one of the auxotype groups, there was no significant difference in the antimicrobial susceptibilities of the gonococcal isolates from black and white patients. Also there was no significant association between the site from which the gonococci were cultured-that is, the cervix, rectum, and urethraand their auxotype or their susceptibility to the four antibiotics.

TABLE I Susceptibility to four antibiotics of Neisseria gonorrhoeae isolates from black and white patients

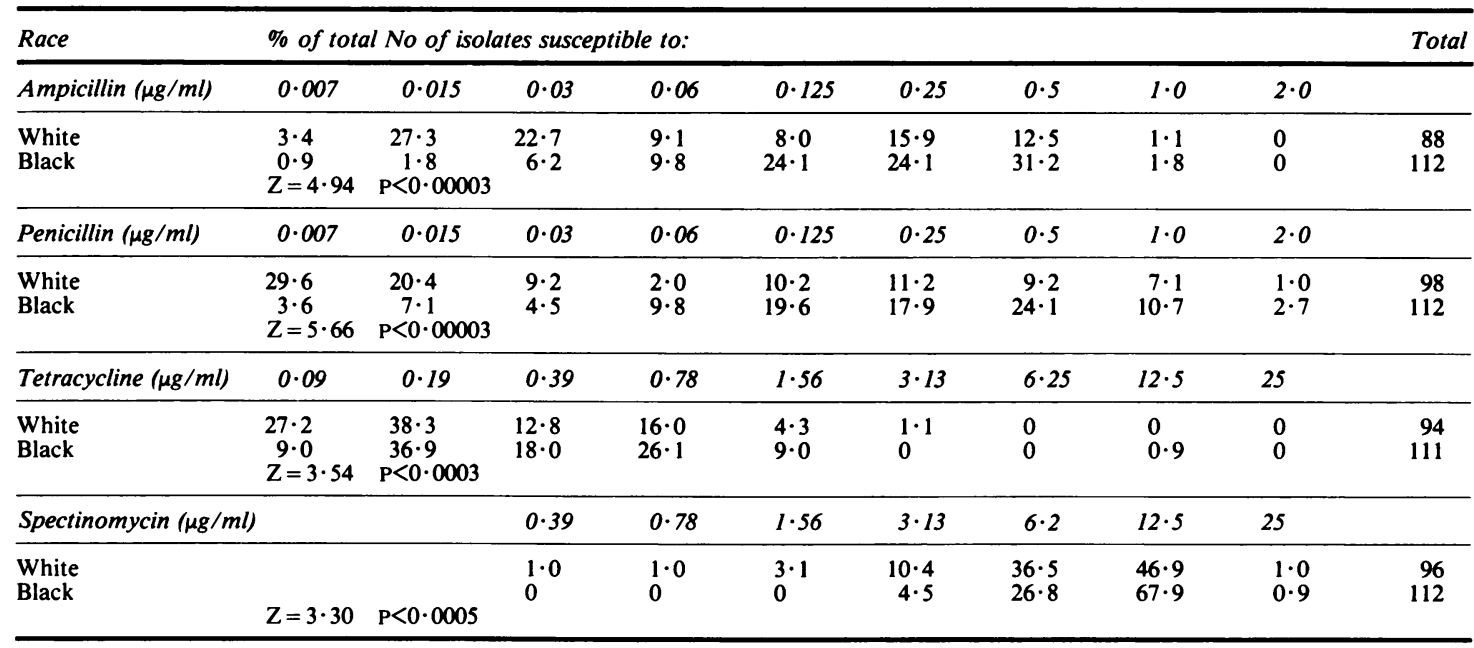

*Normal deviate $\mathrm{Z}$ according to the normal approximation for the Wilcoxin-Mann-Whitney $\mathrm{U}$ test (two-tailed) 
TABLE II Auxotypes of gonococcal isolates from black and white patients

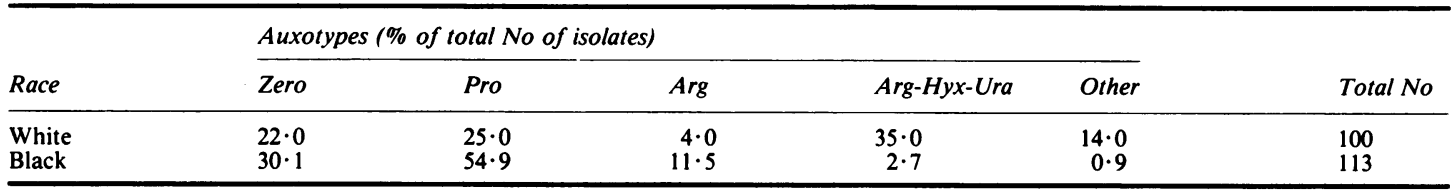

$\chi_{4}^{2}=60 \cdot 79 ; \mathrm{P}<0 \cdot 001$

TABLE III Susceptibility to four antibiotics of auxotypes of Neisseria gonorrhoeae

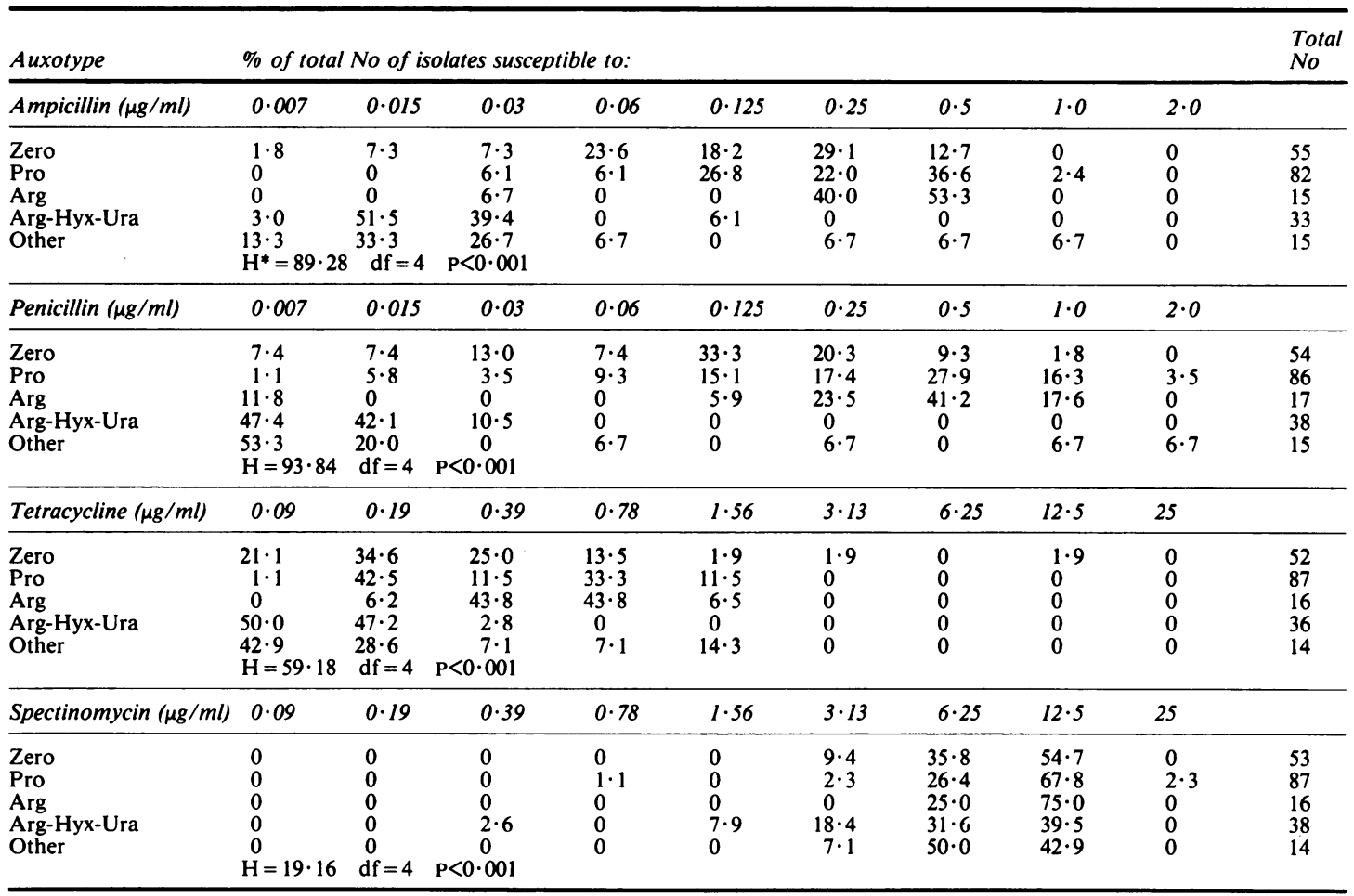

*According to the $\chi^{2}$ approximation to the Kruskal-Wallis $\mathrm{H}$ test

\section{Discussion}

The auxotypes of gonococci infecting black patients differed from those infecting white patients in our clinic. Gonococci of the Pro, Zero, and Arg auxotypes were more common in black patients whereas those of the Arg-Hyx-Ura (AHU) and others were more common in white patients. Pro was the most common auxotype in blacks and AHU was the most common auxotype in whites. Our findings are consistent with those indicating that gonococci of the AHU auxotype are more common in white than black patients attending venereal disease clinics in the United States. ${ }^{89}$ Auxotypes of gonococci from our clinic and from Sweden and the Philippines are compared in Table IV. The AHU auxotype accounted for most of the isolates from Sweden ${ }^{10}$ but

TABLE IV Auxotypes of gonococci isolated from patients in different geographical areas

\begin{tabular}{lccc}
\hline & \multicolumn{3}{c}{$\%$ of strains in each geographical area } \\
\cline { 2 - 4 } Auxotype & Lexington & Sweden 10 & Philippines $^{11}$ \\
\hline Zero & $26 \cdot 3$ & $15 \cdot 7$ & $60 \cdot 2$ \\
Pro & $40 \cdot 8$ & $12 \cdot 7$ & $38 \cdot 5$ \\
Arg & $8 \cdot 0$ & $1 \cdot 9$ & 0 \\
AHU & $17 \cdot 8$ & $40 \cdot 1$ & 0 \\
Other & $7 \cdot 0$ & $29 \cdot 6$ & $1 \cdot 3$ \\
Total No & 213 & 166 & 78 \\
\hline
\end{tabular}


was absent in the isolates from the Philippines, where the Zero and Pro auxotypes were more common. ${ }^{11}$ Although the racial distribution of the patients was not given in these two studies, it is likely that gonococci from the Philippines originated from predominantly non-white patients and the gonococci from Sweden were cultured from predominantly white patients. Thus, the race of the patient may be a factor in the geographical variation of gonococcal auxotypes.

Gonococci of the Pro, Zero, and Arg auxotypes were less susceptible to the four antibiotics compared with those of the other auxotypes. Similar differences in the susceptibility to penicillin of gonococci of these auxotypes have been found by other workers. ${ }^{8} 911-14$ Gonococci of the AHU auxotype are the most susceptible to penicillin and those of the Pro auxotype generally the most resistant to penicillin compared with those of the other auxotypes. If susceptibility to antibiotics is associated with certain gonococcal auxotypes, the changes in susceptibility of gonococci to antibiotics over a period of years may be the result of changes in the prevalence of particular auxotypes. For example, the increased prevalence of gonococci susceptible to penicillin in North Carolina from 1973 to 1978 could be accounted for by the increasing prevalence of AHU strains. ${ }^{5}$ Also the presence of certain auxotypes may result in differences in the antibiotic susceptibility of gonococci in various geographical areas. In general, gonococci with relative penicillin resistance are uncommon in northern Europe but quite common in the Far East, ${ }^{16}$ and this is consistent with the auxotyping data presented in Table IV.

We have not attempted in this study to examine behavioural, social, or genetic factors that might be responsible for the difference in the incidence of gonorrhoea or for the presence of different auxotypes in the two patient groups. In data from public venereal disease clinics, there is a possibility of bias in the selection of patients because of the unequal use of the facilities by blacks and whites. ${ }^{2}$ Black men delay seeking treatment longer than white men after the onset of genitourinary symptoms. ${ }^{17}$ If white men received treatment earlier for symptomatic infections, this might favour, in time, a higher proportion of AHU isolates in whites since this auxotype is more commonly associated with asymptomatic gonorrhoea in men. ${ }^{8}$ However, this would not explain the relative rarity of this auxotype in blacks. If blacks received inadequate doses of antibiotics before their clinic visit and whites did not, this might also explain the low incidence of $\mathrm{AHU}$ isolates in blacks, since the AHU isolates are highly susceptible to antibiotics. However, in another study from our clinic performed at the same time as the present study, we found that the ingestion of antibiotics before the clinic visit was not associated with race. $^{3}$ Social segregation itself is an unlikely cause of microbiological segregation of gonococci, because there was considerable overlap in both groups in the auxotypes more commonly found in blacks. Possibly blacks have an increased susceptibility to gonorrhoea as the result of some genetic or other host factor. Racial differences in the colonisation by pathogenic bacteria have been found among patients for whom cultures for staphylococci and meningococci have been performed. ${ }^{18-20}$ Colonisation by both these micro-organisms is more common in whites than in blacks contrary to what might be expected as a result of overcrowding or other factors associated with low socioeconomic status.

Genetic factors, such as the presence of certain blood-group antigens, may play a part in the increased susceptibility of patients to gonorrhoea. Black patients with blood group B had a higher incidence of gonorrhoea than black patients with other blood groups. ${ }^{21}$ Although this observation was confirmed in white patients with blood group B, Miler $e t a l^{22}$ found no such correlation in black patients. Our definition of the two racial groups was based on self-declaration. Determination of histocompatibility antigens might also be useful in the description of this phenomenon. Preferential infection by subpopulations of gonococci in these two groups of patients has implications for the control of gonorrhoea. If antibiotic-resistant gonococci are isolated more frequently from black patients, efforts should be made to examine current treatment and test-of-cure regimens for this group.

We thank Dr Ernst Stolz, Department of Dermatology, and Dr R van Strik, Department of Biostatistics, Erasmus University, Rotterdam for their advice. We are also grateful to Ms A M Noble for her advice and assistance and to Ms Magda de Ridder-Goetjaer for typing the manuscript. This study was made possible through the co-operation of Philip G Weiler, Commissioner of Health, Lexington-Fayette County Health Department, and by grants from the National Institute of Allergy and Infectious Diseases (AI 11304) and from the Alexandrine and Alexander Sinsheimer Fund. We also thank the Journal's statistical referee for his time and effort.

\section{References}

1. Brooks GF, Darrow WW, Day JA. Repeated gonorrhea: an analysis of importance and risk factors. J Infect Dis 1978; 137: 161-9.

2. Brown WJ. Trends and status of gonorrhea in the United States. J Infect Dis 1971; 123: 682-8. 
3. Noble RC, Kirk NM, Slagel WA, Vance BJ, Somes GW. Recidivism among patients with gonococcal infection presenting to a venereal disease clinic. Sex Transm Dis 1977; 4: 39-43.

4. Jaffe HW, Biddle JW, Thornsberry C, et al. National gonorrhoea therapy monitoring study. In vitro antibiotic susceptibility and its correlation with treatment results. $N$ Engl $J$ Med 1976; 294: 5-9.

5. Catlin BW. Nutritional profiles of Neisseria gonorrhoeae, Neisseria meningitidis and Neisseria lactamica in chemically defined media and the use of growth requirements for gonococcal typing. $J$ Infect Dis 1973; 128: 178-94.

6. Martin JE, Lester A. Transgrow a medium for transport and growth of Neisseria gonorrhoeae and Neisseria meningitidis. Health Services and Mental Health Administration Health Reports 1971; 86: 30-3.

7. Siegel S. Nonparametric Statistics for the Behavioral Sciences. New York: McGraw Hill, 1956.

8. Crawford G, Knapp JS, Hale J, Holmes KK. Asymptomatic gonorrhea in men: caused by gonococci with unique nutritional requirements. Science 1977; 196: 1352-3.

9. Knapp JS, Thornsberry C, Schoolnik GA, Wiesner PJ, Holmes KK, Co-operative Study Group. Phenotypic and epidemiologic correlates of auxotype in Neisseria gonorrhoeae. $J$ Infect Dis 1978; 138: 160-5.

10. Moberg I. Auxotyping of gonococcal isolates. In: Danielsson D, Julin L, Mårdh P-A, eds. Genital Infections and their Complications. Stockholm: Almqvist \& Wiksell, 1975; 271-3.

11. Knapp JS, Holmes KK. Disseminated gonococcal infections caused by Neisseria gonorrhoeae with unique nutritional requirements. J Infect Dis 1975; 132: 204-8.

12. Catlin BW, Pace PJ. Auxotypes and penicillin susceptibilities of Neisseria gonorrhoeae isolated from patients with gonorrhea involving two or more sites. Antimicrob Agents Chemother 1977; 12: 147-56.
13. Morello JA, Lerner SA, Bohnhoff M. Characteristics of atypical Neisseria gonorrhoeae from disseminated and localized infections. Infect Immun 1976; 13: 1510-16.

14. Schoolnik GK, Buchanan TM, Holmes, KK. Gonococci causing disseminated gonococcal infection are resistant to the bactericidal action of normal human sera. J Clin Invest 1976; 58: 1163-73.

15. Eisenstein BI, Lee TJ, Sparling PF. Penicillin sensitivity and serum resistance are independent attributes of strains of Neisseria gonorrhoeae causing disseminated infection. Infect Immun 1977; 15: 834-41.

16. Sparling PF. Antibiotic resistance in the gonococcus. In: Roberts RB, ed. The gonococcus. New York: John Wiley and Sons, 1977; 111-35.

17. Darrow WW. Venereal infections in three ethnic groups in Sacramento. Am J Public Health 1976; 66: 446-50.

18. Millian SJ, Baldwin JN, Rheims MS, Weiser HH. Studies on the incidence of coagulase-positive staphylococci in a normal unconfined population. Am J Public Health 1960; 50: 791-8.

19. Noble RC, Cooper RM, Miller BR. Pharyngeal colonisation by Neisseria gonorrhoeae and Neisseria meningitidis in black and white patients attending a venereal disease clinic. $B r J$ Vener Dis 1979; 55: 14-9.

20. Noble WC. Carriage of Staphylococcus aureus and beta hemolytic streptococci in relation to race. Acta Derm Venereol (Stockh) 1974; 54: 403-5.

21. Foster MT, Labrum AH. Relation of infection with Neisseria gonorrhoeae to ABO blood groups. J Infect Dis 1976; 133: 329-30.

22. Miler JJ, Novotny $P$, Walker PD, Harris JRW, MacLennan IPB. Neisseria gonorrhoeae and the ABO isohemagglutinins. Infect Immun 1977; 15: 713-9. 